Case Report

\title{
Giant Cell Reparative Granuloma Presented as Nasal Mass: A Rare Entity
}

\author{
Sampa Choudhury', Sharbori Kundu²
}

${ }^{1}$ Assistant Professor, Department of Pathology, Andaman \& Nicobar Islands Institute of Medical Sciences, Port Blair, Andaman \& Nicobar Islands.

2Post Graduate Trainee, Department of Surgery, Midnapore Medical College and Hospital, Midnapore, West Bengal, India. DOI: https://doi.org/10.24321/2454.8642.202101

\section{I $\quad \begin{array}{llll}\mathbf{N} & \mathbf{F} & \mathbf{O}\end{array}$}

\section{Corresponding Author:}

Sampa Choudhury, Department of Pathology, Andaman \& Nicobar Islands Institute of Medical Sciences, Port Blair, Andaman \& Nicobar Islands. E-mail Id:

dr.sampa.choudhury@gmail.com

Orcid Id:

https://orcid.org/0000-0002-9369-1386

How to cite this article:

Choudhury S, Kundu S. Giant Cell Reparative Granuloma Presented as Nasal Mass: A Rare Entity. Rec Adv Path Lab Med. 2021;7(1\&2):1-3.

Date of Submission: 2021-03-17

Date of Acceptance: 2021-04-06

\section{$\begin{array}{llllllll}\mathbf{A} & \mathbf{B} & \mathbf{S} & \mathbf{T} & \mathbf{R} & \mathbf{A} & \mathbf{C} & \mathbf{T}\end{array}$}

Giant Cell Reparative Granuloma (GCRG) is an unusual non-neoplastic lesion which most commonly involves maxilla and mandible. We present a case of GCRG of the nasal cavity in a young female presented with the complaint of progressively nasal obstruction. Radiological findings are usually nonspecific in this entity, therefore a good clinical, radiological and pathological correlation is needed for final diagnosis and to differentiate it from other giant cell lesions. Surgical excision is the preferred treatment modality over simple curettage.

Keywords: Giant Cells, Granuloma, Nasal Cavity

\section{Introduction}

Giant Cell Reparative Granuloma (GCRG), originally described by Jaffe, is a non-neoplastic osteolytic granulomatous lesion with unknown etiopathogenesis. ${ }^{1}$ It is benign but at times may behave like a locally aggressive process. GCRC most commonly involves mandible and maxilla. Other rare locations are nasal cavity, paranasal sinuses, orbit, cranial vault etc. ${ }^{2,3}$ A number of reactive and neoplastic conditions having osteoclast-like giant cells may mimic this entity which needs to be differentiated by detailed clinical and histological evaluation. ${ }^{9}$ In this article, we presented an unusual case of GCRG in the nasal cavity of a young female.

\section{Case History}

A 27-year-old female presented with complaints of progressively increasing blockage of the left nasal cavity for two months. There was no history of fever, cough, nasal discharge, epistaxis or weight loss. No prior history of trauma was obtained. Examination revealed a fleshy pinkish mass obliterating the nasal cavity. The mass did not bleed to touch.

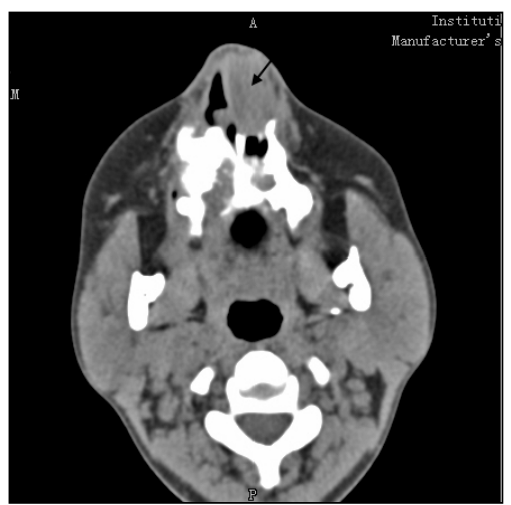

Figure I. Left Vestibule Expansile Mass with Deviated Nasal Septum seen in CECT Scan (arrow) 
Contrast-Enhanced Computed Tomography (CECT) of paranasal sinuses, nose and orbit revealed a well defined, polypoidal lesion measuring $28 \times 23 \times 12 \mathrm{~mm}$ in the left vestibule extending posteriorly into the nasal fossa and was seen to cause scalloping of the left nasal bone and left inferior turbinate. The nasal septum was mildly deviated to the right with a spur to the right. No cortical bone destruction was seen, suggesting a chronic benign lesion. There was no extension of the lesion in the maxillary antrum. No calcification, fat or high density contents were seen in the lesion (Figure 1). Other haematological and serological parameters were within normal limit.

An excision biopsy of the lesion was received; histopathological examination revealed a polypoidal mass lined by stratified squamous epithelium, focal ulceration and mild acute on chronic inflammation. Numerous osteoclastlike giant cells with 20-30 nuclei were seen dispersed within a fibrovascular stroma and were clustering around haemorrhage and blood vessels. No calcification/ bone formation was seen (Figures 2 and 3 ). This case was reported as giant cell reparative granuloma of nasal cavity. The patient was followed up after 4 years of surgical removal and didn't show any evidence of recurrence.

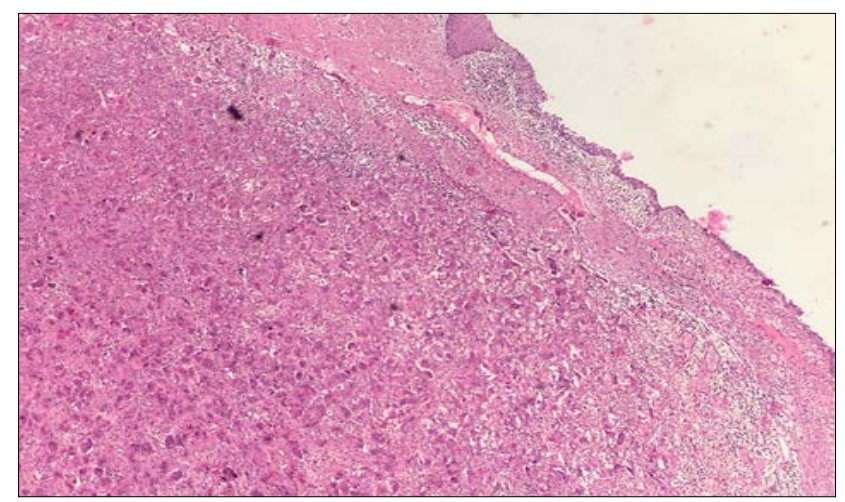

Figure 2.Stratified Squamous Lining with Focal Ulceration, Inflammation and Numerous Giant Cells seen in Microscopic Examination

(Hematoxyline \& Eosin, 4X)

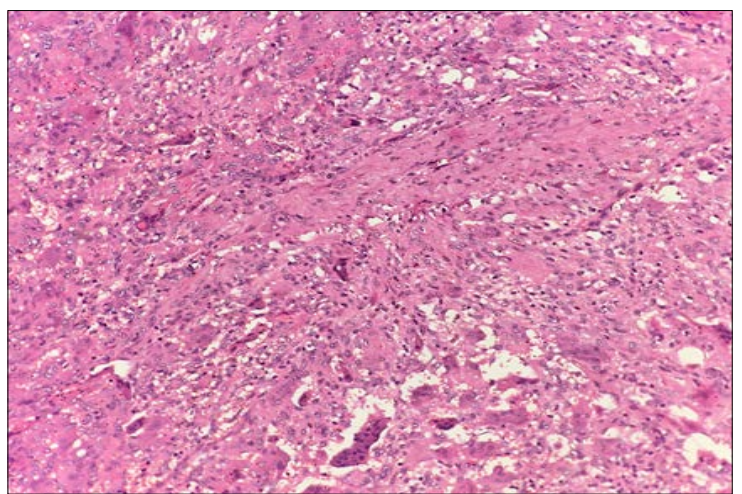

Figure 3(a).Osteoclast like Giant Cells are dispersed in Fibroblastic Stroma (Hematoxyline \& Eosin, 40X)

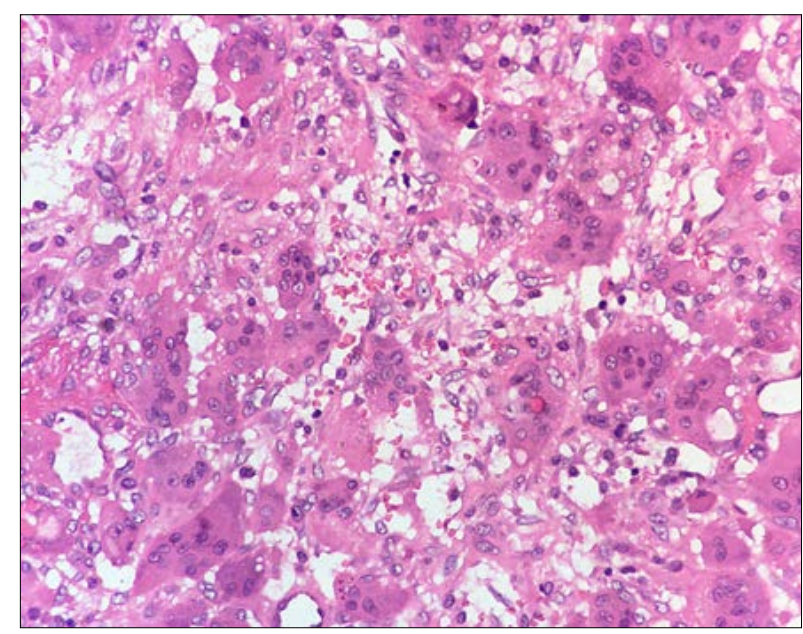

Figure 3(b).Giant Cells Clustered around Blood Vessels (Hematoxyline \& Eosin, 40X)

\section{Discussion}

GCRG is an uncommon benign but occasionally locally aggressive lesion which most commonly involves mandible and maxilla of young females. They are classified as either central or peripheral. Central lesions have a bony covering, and peripheral lesions have soft tissue component and bony resorption. Etiopathogenesis is controversial. Jaffe originally described it as a reactive process to traumainduced haemorrhage or inflammation, whereas others suggested infections or developmental etiologies. ${ }^{3,4}$ Our case is a peripheral, non-aggressive GCRG of nasal cavity in a young female without any prior history of trauma. The most possible pathogenesis may be a reactive process to chronic inflammation.

Clinical presentation differs from case to case depending upon the location of the lesion. Nasal cavity lesion presents as nasal obstruction, epistaxis, proptosis and diplopia; whereas maxillary lesion shows only facial asymmetry and upper jaw swelling. Cranial bone involvement e.g. temporal bone lesions present as hearing loss, tinnitus, vertigo and sphenoid bone lesions present as diplopia, loss of vision and headache. ${ }^{1,5,6}$

Radiological findings are usually nonspecific, osteolytic or trabeculated lesions that cannot differentiate GCRG from other soft tissue and intraosseous lesions. CT scan shows expandable mass which may erode bone cortex and occasionally may extend to intracranially or orbit through bone destruction of ethmoid sinus, sphenoid bone or temporal bone. Particularly, GCRG of small bones of hands and feet is very difficult to differentiate from giant cell tumour radiologically. Magnetic Resonance Imaging (MRI) of intracranial lesions shows a heterogenous enhanced mass with focal cystic or fluid-filled areas. ${ }^{2,6,7}$ In our case, a polypoidal mass in the left nasal cavity with deviated nasal septum was identified on contrast-enhanced CT scan. There 
was no bony erosion, calcification or osteoid in the lesion. Histologically, the lesion shows irregularly distributed osteoclastic giant cells clustering around haemorrhage or hemosiderin deposition. These giant cells have fewer nuclei than giant cells of a giant cell tumour and are surrounded by fibrous bands. Reactive bone formation can also be noted. ${ }^{7,9}$

Differential diagnoses include a number of reactive, neoplastic or metabolic lesions having osteoclastic giant cells e.g. Giant Cell Tumour (GCT), brown tumour of hyperparathyroidism, Aneurysmal Bone Cyst (ABC), etc. GCT should be differentiated from GCRG, as outcome and treatment planning is quite different in those two conditions. Histologically, GCTs is composed of a mixture of mononuclear round to spindle-shaped cells and giant cells having a large number of nuclei (up to 20-50 nuclei). On the other hand, Brown tumour of hyperparathyroidism, which shows similar features as GCRG histologically, is characterised by hypercalcemia, elevated levels of parathyroid hormone and multiple osteolytic lesions. ${ }^{9}$ $A B C s$ are non-neoplastic, eccentric cystic lesions that may rarely involve facial bone and are characterised by bloodfilled spaces fibroblastic connective tissue, giant cells and reactive woven bone. ${ }^{2}$ Therefore, confirmatory diagnosis of GCRG needs a good correlation of clinical, biochemical, radiological and histopathological findings.

The most well-accepted standard treatment procedure of GCRG is surgical excision and debulking. Surgical excision is preferred over simple curettage because of a high recurrence rate. Calcitonin, alpha-IFN and steroid therapies are non-surgical options for an aggressive type of GCRG. Calcitonin acts on giant cells and reduces abnormal bone turnover by inhibiting osteoclastogenesis. ${ }^{6}$ Interferon is an anti-angiogenic agent which gives some success in other studies, its use is limited due to adverse effects. ${ }^{8}$ Intralesional administration of steroids inhibits lysosomal protease release from giant cells and induces apoptosis, but the outcome of several studies are not satisfactory. These non-surgical options can reduce the rapid growth of tumour, but should be followed by surgery to eliminate the lesion. Lastly, radiation therapy is reserved for inoperable tumours which may also raise a concern for sarcomatous transformation. ${ }^{5}$

\section{Acknowledgement}

The authors acknowledge the help of histopathology laboratory staffs of ANIIMS, Port Blair.

\section{Financial Support: None}

\section{Conflict of Interest: None}

\section{References}

1. Garg P, Jain J, De N, Chatterjee K. A central giant cell granuloma in posterior part of maxilla- a case report.
Int J Surg Case Rep. 2017;30:222-5. [PubMed] [Google Scholar]

2. Lingaiah J, Ganji L, Yella S, Thatikonda KR. A rare case of reparative granuloma of nasal cavity. Int J Otolaryngol Head Neck Surg. 2014;3:293-7. [Google Scholar]

3. Williams JC, Thorell WE, Treves JS, Fidler ME, Moore GF, Leibrock LG. Giant cell reparative granuloma of the petrous temporal bone: a case report and literature review. Skull Base Surg. 2000;10:89-93. [PubMed] [Google Scholar]

4. Morris JM, Lane JI, Witte RJ, Thompson DM. Giant cell reparative granuloma of the nasal cavity. AJNR Am J Neuroradiol. 2004;25:1263-5. [PubMed] [Google Scholar]

5. Ishinaga H, Otsu K, Mouri G, Takeuchi K. Aggressive giant cell reparative granuloma of the nasal cavity. Case Rep Otolaryngol. 2013;2013:690194. [PubMed] [Google Scholar]

6. Jamil OA, Lechpammer M, Prasad S, Litvack Z, Dunn IF. Giant cell reparative granuloma of the sphenoid: case report and review of the literature. Surg Neurol Int. 2012;3:140. [PubMed] [Google Scholar]

7. Yu JL, Qu LM, Wang J, Huang HY. Giant cell reparative granuloma in the temporal bone of the skull base: report of two cases. Skull Base. 2010;20:443-8. [PubMed] [Google Scholar]

8. Gulati D, Bansal V, Dubey P, Pandey S, Agrawal A. Central giant cell granuloma of posterior maxilla: first expression of primary hyperparathyroidism. Case Rep Endocrinol. 2015;2015:170412. [PubMed] [Google Scholar]

9. Bovee J, Andrea C. Bone tumors. In: Mills SE, Greenson JK, Hornick JL, Longacre TA, Reuter VE, editors. Sternberg's Diagnostic Surgical Pathology. 6th ed. Philadelphia: Lippincott Williams \& Wilkins; 2015. p. 297-9. 